\title{
Effects of metal nanoparticles on freshwater rotifers may persist across generations
}

\author{
Nuno Martins ${ }^{\mathrm{a}, \mathrm{b}, *}$, Arunava Pradhan ${ }^{\mathrm{a}, \mathrm{b}}$, Cláudia Pascoal ${ }^{\mathrm{a}, \mathrm{b}}$, Fernanda Cássio ${ }^{\mathrm{a}, \mathrm{b}}$ \\ ${ }^{a}$ Centre of Molecular and Environmental Biology (CBMA), Department of Biology, University of Minho, Campus de Gualtar, 4710-057, Braga, Portugal \\ ${ }^{\mathrm{b}}$ Institute of Science and Innovation for Bio-sustainability (IB-S), University of Minho, Campus de Gualtar, 4710-057, Braga, Portugal
}

\section{A R T I C L E I N F O}

\section{Keywords:}

Ag-NPs

CuO-NPs

Metal ions

Freshwater rotifers

Oxidative stress

Transgenerational effects

\begin{abstract}
A B S T R A C T
Nanotechnology has become one of the fastest growing industries in the current century because nanomaterials (NMs) are present in an ever-expanding range of consumer products increasing the chance of their release into natural environments. In this study, the impacts of two metal nanoparticles (Ag-NPs and CuO-NPs) and their equivalent ionic forms $\left(\mathrm{Ag}^{+}\right.$and $\mathrm{Cu}^{2+}$ ) were assessed on the lentic freshwater rotifer Brachionus calyciflorus and on its ability to adapt and recover through generations. In our study, Ag-NPs and CuO-NPs inhibited the rotifer population growth rate and caused mortality at low concentrations $\left(<100 \mu \mathrm{g} \mathrm{L}^{-1}\right)$. Ag-NPs and CuO-NPs decreased in the medium when organisms were present (48 h exposure: $51.1 \%$ and $66.9 \%$, respectively), similarly $\mathrm{Ag}^{+}$and $\mathrm{Cu}^{2+}$ also decreased from medium in presence of the organisms (48 h: $35.2 \%$ and $47.3 \%$, respectively); although the metal concentrations removed from the medium were higher for nanoparticles than metal ions, metal ions showed higher effects then their respective nanoparticle forms. Rotifer populations exposed for 4 generations to the toxicants were able to recover the population growth rate, but some rotifers showed developmental delay and inability to reproduce even after the removal of the toxicants. Intracellular accumulation of reactive oxygen species as well as plasma membrane damage were found in the rotifers at concentrations corresponding to $\mathrm{EC}_{10}\left(\mathrm{Ag}-\mathrm{NPs}=1.7 \mu \mathrm{g} \mathrm{L}^{-1}, \mathrm{Ag}^{+}=4.5 \mu \mathrm{g} \mathrm{L}^{-1}\right.$, CuO-NPs $=46.9 \mu \mathrm{g} \mathrm{L}^{-1}, \mathrm{Cu}^{2+}=35$ $\mu \mathrm{g} \mathrm{L}^{-1}$ ) of the population growth rate. Our results showed, for the first time, that effects of metal nanoparticles and metal ions on rotifer populations may persist along several generations. This should be taken into account when assessing risks of metal nanoparticles in freshwaters.
\end{abstract}

\section{Introduction}

Nanotechnology is one of the rapidly growing industries of the 21st century (Bondarenko et al., 2013), expanding its influence on several fields, including medicine (Barnett et al., 2007), cosmetics (Lens, 2009), renewable energies (Wei et al., 2008), environmental remediation (Tungittiplakorn et al., 2004) and electronic devices (Kachynski et al., 2008). The increasing production, consumption and release of nanomaterials with unique physico-chemical properties (Moore, 2006) into the aquatic environment have raised concern on their behaviour and toxicity, posing a new challenge to the environment and human health (Darlington et al., 2009).

Ag-NPs and CuO-NPs are among the most commercially used metal nanoparticles, encompassing a large variety of applications in various fields. Ag-NPs are mostly used in inks, textiles, soaps, microelectronics and medical imaging (Frattini et al., 2005; Wu et al., 2006; Jain et al., 2008; Perelaer et al., 2009). The growing market of Ag-NPs is mainly associated with the antimicrobial activity of silver (Luoma, 2008) and with its low cost of production (Capek, 2004). On the other hand, CuO-NPs are used, for example, in semiconductors, electronic chips, solar cells, lithium batteries, gas sensors and as antimicrobial agents (Ren et al., 2009; Bondarenko et al., 2013).

Data on concentrations of Ag-NPs and CuO-NPs in aquatic environments are scarce. Predicted environmental concentrations of Ag-NPs range from 0.0028 to $0.619 \mu \mathrm{g} \mathrm{L}^{-1}$ (Musee, 2011) in surface waters, but much lower concentrations $\left(0.3-6.6 \mathrm{ng} \mathrm{L}^{-1}\right)$ were reported in the Meuse River from the Netherlands (Peters et al., 2018). Few information exists on CuO-NPs environmental concentrations, but copper concentration in industrial wastewaters can exceed $100 \mathrm{mg} \mathrm{L}^{-1}$ with almost half of the concentration corresponding to CuO-NPs (Huang et al.,

\footnotetext{
* Corresponding author at: Centre of Molecular and Environmental Biology (CBMA), Department of Biology, University of Minho, Campus de Gualtar, 4710-057, Braga, Portugal.

E-mail address: nunoepbmartins@gmail.com (N. Martins).
} 
2006).

Some studies have shown negative effects of Ag-NPs and CuO-NPs on freshwater organisms from producers (e.g. Raphidocelis subcapitata), primary consumers (e.g. Daphnia magna) to secondary consumers (e.g. Pimephales promelas) (Garner et al., 2015), with evidence that at least part of the nanoparticle toxicity is due to oxidative stress (Pradhan et al., 2015). Despite these reports, the potential impacts of metal NPs in aquatic systems are still uncertain. The European Chemicals Agency, US Environmental Protection Agency and World Health Organization are trying to establish directives and legal frameworks to protect the quality of freshwaters from these emergent chemical contaminants (Esplugas et al., 2007).

Freshwater rotifers are relatively small $(<200 \mu \mathrm{m})$ metazoan invertebrates that are widely distributed and are ecologically relevant because to their role in secondary production in lentic ecosystems (Wallace, 2002; Dahms et al., 2011). The ease of cultivation and laboratory maintenance, small size, preferably parthenogenic reproduction, high population density, short generation time, and sensitivity to a vast range of toxicants (Hagiwara et al., 1997; Gómez et al., 2002; Hagiwara et al., 2007) increase the potential of rotifers as model organisms for ecotoxicological tests.

Standard laboratory bioassays with rotifers include acute (ASTM, 2002) and chronic tests (Snell and Janssen, 1995) that mainly focuses on assessing mortality and reproduction (population growth rate). At cellular level, endpoints such as oxidative stress have shown to be a suitable biomarker in the rotifer model (Dahms and Hellio, 2009). The monogonont rotifer $B$. calyciflorus has been used for ecotoxicity tests for a large variety of xenobiotics, including metals and nanoparticles, and has proven suitable to allow quick data collection at lethal and sub-lethal level (Marcial et al., 2005; Snell and Hicks, 2011).

Metals and emergent contaminants have been reported to induce negative transgenerational effects on terrestrial and freshwater invertebrates (Yu et al., 2013; Castro et al., 2018) most of which are likely to be the consequences of epigenetic changes (Vandegehuchte et al., 2010; Baker et al., 2014). Castro et al. (2018) showed adverse effects in the fitness of the F1 generation of Daphnia magna after maternal exposure to paracetamol and copper sulphate. Also, microplastics had multigenerational effects causing the extinction of $D$. magna populations in 2 exposed generations, but when F1 was released from contaminants, a recovery was observed up to the F3 generation (Martins and Guilhermino, 2018). The knowledge on the transgenerational effects of NPs to freshwater invertebrates is limited (Yu et al., 2013; Schultz et al., 2016; Rossbach et al., 2019; Fan et al., 2019), however, this information can be relevant since metal NPs can persist in the environment and can exert effects throughout generations.

This study aims to evaluate the lethal and sub-lethal effects of two metal nanoparticles (Ag-NPs and CuO-NPs) on rotifer populations by assessing if and how i) environmentally relevant concentrations can affect the fitness and population size, and ii) future generations can be affected by the parental exposure. We hypothesised that i) NPs would exhibit lethal and sub-lethal effects towards rotifer populations, ii) toxicity could be related to oxidative stress and plasma membrane damage, even at very low exposure concentrations, and iii) effects would increase along generations if continuously exposed, but would be attenuated along generations when offsprings are released from NP exposure.

\section{Materials and methods}

\subsection{Culture and maintenance of rotifers}

Rotifer populations were fed on Raphidocelis subcapitata cultures, which were maintained in $2 \mathrm{~L}$ flasks in COMBO algae modified medium (Kilham et al., 1998; Table S1), with constant aeration (filtered through a syringe filter with $0.2 \mu \mathrm{m}$ ) at $20 \pm 1{ }^{\circ} \mathrm{C}$ and continuous light. The medium and materials were sterilised in an autoclave $\left(30 \mathrm{~min}\right.$ at $120^{\circ} \mathrm{C}$ and 5 bar).

B. calyciflorus was obtained from MicroBioTests Inc. as dormant cysts and were stored at $4{ }^{\circ} \mathrm{C}$ in darkness and hatched on demand. A standard freshwater medium $\left(96 \mathrm{mg} \mathrm{L}^{-1}\right.$ of $\mathrm{NaHCO}_{3}, 60 \mathrm{mg} \mathrm{L}^{-1}$ of $\mathrm{CaSO}_{4} \cdot 2 \mathrm{H}_{2} \mathrm{O}$, $60 \mathrm{mg} \mathrm{L}^{-1}, 60 \mathrm{mg} \mathrm{L}^{-1}$ of $\mathrm{MgSO}_{4} \cdot 7 \mathrm{H}_{2} \mathrm{O}$ and $4 \mathrm{mg} \mathrm{L}^{-1}$ of $\mathrm{KCl}$; Table S2) with moderately hard water (U.S. Environmental Protection Agency, 1985) was prepared to hatch the cysts. Values of ionic strength in the standard freshwater medium did not vary with time and with the addition of contaminants $(\mathrm{pH}=7.5 \pm 0.3$, conductivity $=250 \pm 0.5$ $\mu \mathrm{S} / \mathrm{cm}$ ). Hatching was done in $10 \mathrm{~mL}$ of standard freshwater medium in a climate chamber for $16-18 \mathrm{~h}$ at $25{ }^{\circ} \mathrm{C}$ with continuous illumination. Before assays, freshly hatched rotifers were fed with Roti-Rich ${ }^{\mathrm{TM}}$ suspension.

\subsection{Stock suspensions and characterization of metal nanoparticles}

Aqueous suspension of citrate-coated Ag-NPs (1 $\mathrm{g} \mathrm{L}^{-1} ; 20-30 \mathrm{~nm}$ size) was purchased from NanoSys GmbH (Wolfhalden, Switzerland). A stock suspension of $20 \mathrm{mg} \mathrm{L}^{-1}$ was prepared in standard freshwater medium, vortexed for $2 \mathrm{~min}$, to disperse the nanoparticles, and stored in the absence of light until use. The stock suspension was diluted in the standard freshwater medium to prepare each nominal concentration. Stock suspension $\left(80 \mathrm{mg} \mathrm{L}^{-1}\right.$ ) of CuO-NPs ( $<50 \mathrm{~nm}$ powder of $99.5 \%$ spherical CuO-NPs; Sigma-Aldrich) was prepared in standard freshwater medium, vortexed and stored in the dark until use.

Silver nitrate (BioXtra, $>99 \%$, titration) $\left(\mathrm{AgNO}_{3}\right.$, CAS Number: 7761-88-8) and copper chloride dihydrate (ACS reagent, $\geq 99 \%$ ) $\left(\mathrm{CuCl}_{2} .2 \mathrm{H}_{2} \mathrm{O}\right.$, CAS Number: $\left.10125-13-0\right)$ were purchased from SigmaAldrich. Stock solutions of $\mathrm{Ag}^{+}$and $\mathrm{Cu}^{2+}$ were prepared as those of $\mathrm{Ag}$ NPs and CuO-NPs.

The hydrodynamic size distribution (HDD), zeta potential, and polydispersity index (PDI) of Ag-NPs and CuO-NPs in suspensions at the highest concentrations $\left(500 \mu \mathrm{g} \mathrm{L}^{-1}\right.$ of $\mathrm{Ag}$ and $2000 \mu \mathrm{g} \mathrm{L}^{-1}$ of $\mathrm{Cu}$ respectively) were monitored by dynamic light scattering (Malvem Zetasizer Nano ZS; Malvern Instruments). HDD samples were prepared as follows: i) T0 (beginning of the exposure) and T48 (end of the exposure) without rotifers or algae, and ii) $\mathrm{T} 0$ and $\mathrm{T} 48$ with rotifers and algae. In well plates, 1 rotifer per $\mathrm{mL}$ and $2 \times 10^{6}$ cells per $\mathrm{mL}$ of algae food (Raphidocelis subcapitata) were added to each treatment (3 replicates). Samples for DLS were collected at each time (T0 and T48) and filtered through $0.22 \mu \mathrm{m}$ syringe filter to remove rotifers and algae in does experimental conditions.

Samples for metal quantification in nanoparticles and ionic forms were prepared as for DLS measurements. Samples were acidified $\left(\mathrm{HNO}_{3}\right.$, $5 \% \mathrm{v} / \mathrm{v}$ ) prior to metal quantification by inductively coupled plasma mass spectrometry (ICP-MS) at Scientific and Technological Research Assistance Centre, University of Vigo, Spain. Figures of merit can be found in Table S8.

Metal quantification was assessed as above under the following conditions: i) T0 (beginning of the exposure) and T48 (end of the exposure) without rotifers or algae, and ii) $\mathrm{T} 0$ and $\mathrm{T} 48$ with rotifer and algae (3 replicates).

Parallel to metal quantification, samples for assessing metal dissolution from nanoparticles were prepared as above under the following conditions: T0 without organisms, T0 with organisms, T48 without organisms and T48 with organisms (3 replicates). Samples were loaded in Amicon Ultra-15 centrifugal filter units ( $3 \mathrm{kDa}$ m.w. cut-off: $<2 \mathrm{~nm}$ of estimated pore size; Merck Millipore, Germany) and centrifuged at 7500 g. 30 min: 3 times) to quantify dissolved metals by ICP-MS. Maximum nominal concentrations of Ag-NPs as total Ag: $500 \mu \mathrm{g} \mathrm{L}^{-1} ; \mathrm{Ag}^{+}: 500 \mu \mathrm{g} \mathrm{L}^{-}$ ${ }^{1}$; CuO-NPs as total Cu: $2000 \mu \mathrm{g} \mathrm{L}^{-1} ; \mathrm{Cu}^{2+}: 2000 \mu \mathrm{g} \mathrm{L}^{-1}$ were chosen to guarantee inhibition of population growth rate at $100 \%$.

\subsection{Mortality and reproduction assays}

For $24 \mathrm{~h}$ rotifer mortality test, we assessed the toxicity of Ag-NPs, 
$\mathrm{Ag}^{+}$, CuO-NPs and $\mathrm{Cu}^{2+}$ to $\mathrm{B}$. calyciflorus (ISO, 2001) by placing 5 juveniles in each well in 24 multi-well test plates. We used 8 concentrations of each contaminant (Ag-NPs as total Ag: 0.8-500 $\mu \mathrm{g} \mathrm{L}^{-1} ; \mathrm{Ag}^{+}$: 0.8-500 $\mu \mathrm{g} \mathrm{L}^{-1}$; CuO-NPs as total Cu: $39.1-5000 \mu \mathrm{g} \mathrm{L}^{-1}$; $\mathrm{Cu}^{2+}: 2.3-40 \mu \mathrm{g}$ $\mathrm{L}^{-1}$ ) and a negative control with 4 replicates each, in a test volume of 1 $\mathrm{mL}$ per well. No feeding was done prior or during the $24 \mathrm{~h}$ test.

At $48 \mathrm{~h}$ sub-lethal test, we assessed the toxicity of Ag-NPs, CuO-NPs, $\mathrm{Ag}^{+}$and $\mathrm{Cu}^{2+}$ to reproduction and population growth of $B$. calyciflorus (ISO, 2001). After hatching, 1 juvenile of $B$. calyciflorus was placed each well in 24 multi-well test plates. We used 8 concentrations of the contaminants (Ag-NPs as total Ag: 1.56-200 $\mu \mathrm{g} \mathrm{L}^{-1} ; \mathrm{Ag}^{+}: 1.56-200 \mu \mathrm{g} \mathrm{L}^{-1}$; CuO-NPs as total Cu: $15.62-2000 \mu \mathrm{g} \mathrm{L}^{-1} ; \mathrm{Cu}^{2+}$ : $1.56-200 \mu \mathrm{g} \mathrm{L}{ }^{-1}$ ) and controls with 8 replicates each in a volume of $1 \mathrm{~mL}$ per well. Rotifers were feed $2 \mathrm{~h}$ prior to its introduction into the wells with Roti-Rich ${ }^{\mathrm{TM}}$ pre-feeding suspension and during the experimental period with a fresh suspension of the green algae $R$. subcapitata $\left(2 \times 10^{6}\right.$ cells per $\left.\mathrm{mL}\right)$. Both assays were performed at $25{ }^{\circ} \mathrm{C}$ in the absence of light. At the end of the experiments, the total number of living and dead organisms per well was counted under a dissection microscope (Leica S8APO).

Population growth rate $(r)$ was calculated as:

$\mathrm{r}=\left(\ln \mathrm{N}_{\text {final }}-\ln \mathrm{N}_{\text {start }}\right) / \mathrm{T}$

Where:

$\mathrm{N}_{\text {final }}=$ mean number of rotifers after $2 \mathrm{~d}$ incubation

$\mathrm{N}_{\text {start }}=$ mean number of rotifers at $\mathrm{T} 0(=1)$

$\mathrm{T}=$ time of exposure in days $(=2)$

The validation of the test was achieved when the mean population growth rate of controls $>0.55 \mathrm{~d}^{-1}$, the average percentage of effect at the lowest concentration $<50 \%$ and reproduction occurred in at least 7 of the 8 replicates in the control.

\subsection{Reactive oxygen species assessment}

Ten juveniles were placed in each well in 6 multi-well plates, in a volume of $5 \mathrm{~mL}$ of standard freshwater medium per well (Table S1). Modelled concentrations as $\mathrm{EC}_{10}$ (effect concentration reducing $10 \%$ of population growth rate) were tested against a negative control with clean freshwater medium ( 6 replicates) for a period of $48 \mathrm{~h}$. After this period rotifers were frozen with liquid nitrogen and stored in $-80{ }^{\circ} \mathrm{C}$.

The rotifers from this $48 \mathrm{~h}$ sub-lethal test were prepared with the following fluorescence markers: $5 \mu \mathrm{M}$ CM- $\mathrm{H}_{2}$ DCFDA, $15 \mu \mathrm{M}$ propidium iodide and $100 \mu \mathrm{L}$ of the anti-fading reagent containing 4',6-diamidino2-phenylindole (DAPI). Rotifers were unfrozen, centrifuged $(10,000 \mathrm{~g}$ for $5 \mathrm{~min}$ ) to remove the excess of medium. Then, rotifers were suspended in freshwater medium and incubated with $\mathrm{CM}-\mathrm{H}_{2}$ DCFDA and propidium iodide for $15 \mathrm{~min}$ in the dark. After this period, the dye was removed by centrifugation $(10,000 \mathrm{~g} ; 5 \mathrm{~min})$, and clean freshwater medium was added to resuspend rotifers. Finally, the anti-fading reagent was added before loading the samples onto the microscope slides. Each slide was scanned through an epifluorescence microscopy $(160 \times$ and $200 \times$, Leica DM5000B), and images were acquired with a digital camera (Leica DFC 350 FX R2) using the software LAS AF (Ver. 1.4.1).

\subsection{Transgenerational assay}

An adapted version of the $48 \mathrm{~h}$ rotifer reproduction test was performed to assess the toxicity of Ag-NPs, $\mathrm{Ag}^{+}, \mathrm{CuO}-\mathrm{NPs}$ and $\mathrm{Cu}^{2+}$ on the population growth and maturity state of $B$. calyciflorus through the generations over a period of 10 days. For all tested NPs and ions, the modelled $\mathrm{EC}_{50}$ was used as the exposure concentration. At the start of the experiment, $\mathrm{F} 0$ generation was exposed to $\mathrm{EC}_{50}$ concentration of each contaminant (Ag-NPs, $\mathrm{Ag}^{+}, \mathrm{CuO}-\mathrm{NPs}$ and $\mathrm{Cu}^{2+}$ ) for $48 \mathrm{~h}$. At $48 \mathrm{~h}$, freshly born rotifers (less than $24 \mathrm{~h}$ old) were transferred to new wells to start the exposure of the $\mathrm{F} 1$ generation. From each replicate, one rotifer was exposed to contaminants (Ag-NPs, $\mathrm{Ag}^{+}$, CuO-NPs and $\mathrm{Cu}^{2+}$ ) and another rotifer was released from contaminants by transferring it to clean medium. At the end of the new $48 \mathrm{~h}$ (F1 generation), one rotifer with less than $24 \mathrm{~h}$ was transferred to a new contaminant treatment in order to start the F2 generation (Fig. S1). This procedure was repeated until reaching the F4 generation. At the end of each $48 \mathrm{~h}$, live and dead rotifers were recorded to estimate population growth rate, and rotifers with more than $24 \mathrm{~h}$ were sampled and frozen for assessing the intracellular ROS accumulation and plasma membrane damage as described above (see 2.4).

\subsection{Data analyses}

Significant differences in metal concentrations at the beginning (T0) and at the end of the experiment (T48) were determined by a $t$-test. Significant differences in metal removal from the medium by organisms and in metal dissolution from nanoparticles were determined by twoaway ANOVAs (Table S6 and Table S7) followed by Tukey's multiple comparison post-hoc tests. To test if the hydrodynamic size, zeta potential or PdI varied with the exposure time and the presence of rotifers and algae, two-way ANOVAs were used (Table S3), followed by Tukey's multiple comparison post-hoc tests.

Effect concentrations $\left(\mathrm{EC}_{10}, \mathrm{EC}_{20}\right.$ and $\left.\mathrm{EC}_{50}\right)$ with respective $95 \%$ confidence limits were calculated by Probit regression (Finney, 1971) for mortality data (using SPSS statistics 17.0) and by logistic regression for population growth rate (using STATISTICA 8.0 software). The determination of NOEC (no-observed-effect-concentration) and LOEC (low-observed-effect-concentration) of each contaminant for mortality and population growth rate were estimated by one-way ANOVA (Table S4), followed by the Dunnett's test to identify treatments that differed significantly from the control.

For each generation in the transgenerational test, the effects of each contaminant on exposed or pre-exposed rotifers were assessed by oneway ANOVAs (Table S5) followed by the Dunnett's tests. All ANOVAs and $t$-test analysis were performed in GraphPad Prism 7.

\section{Results}

\subsection{Characterization of nanoparticles and quantification of metal} concentrations

In the absence of rotifers and algae, no change in metal concentration in the medium was observed along time ( $t$-test $P>0.05)$. Metal concentration in the medium at T0 in the absence of rotifers and algae was used as the initial concentration, to calculate the percentage of metal in the medium (Fig. S2). At T0, the presence of rotifers and algae led to a significant decrease $(P<0.05)$ in metal concentration for all metal forms, and this decrease was higher for nanoparticles than for their ionic forms $(P<0.05$; Fig. S2). Rotifers and algae accumulated and/or removed a significant amount of CuO-NPs from the medium with time (T0 $=48.7 \pm 2.8 \%$ versus T48 $=66.9 \pm 1.5 \% P>0.05$; Fig. S2). Rotifers and algae also reduced significantly $\mathrm{Cu}^{2+}$ concentration in the medium with time $\left(\mathrm{Cu}^{2+}\right.$ removal $\mathrm{T} 0=23.1 \pm 1 \%$ to $\mathrm{T} 48=47.3 \pm 1.4$ $\%, P<0.05$; Fig. S2). On the other hand, concentration of Ag-NPs and $\mathrm{Ag}^{+}$in the medium decreased with time in the presence of rotifers and algae $\left(\mathrm{Ag}-\mathrm{NP} \mathrm{T} 0=64.6 \pm 2.3 \%\right.$ to $\mathrm{T} 48=51.1 \pm 1.7 \% ; \mathrm{Ag}^{+} \mathrm{T} 0=46.2 \pm$ $2.1 \%$ to T48 $=35.2 \pm 0.7 \%$, $t$-test; $P<0.05$; Fig. S2).

The presence of rotifers and algae had significant effects on average HDD of Ag-NPs (two-way ANOVA, $P<0.05$ ), while exposure time showed no significant effect $(P>0.05)$. Significant decrease in the HDD of Ag-NPs was observed in the presence of rotifers and algae at the beginning (T0: from $152.8 \mathrm{~nm}$ to $113.7 \mathrm{~nm}, P<0.05$; Fig. 1) and at the end of exposure (T48: from 143.4-124.1 nm, $P<0.05$; Fig. 1). Zeta potential of Ag-NPs was affected by time and by the presence of organisms (two-away ANOVA, $P<0.05$; Fig. 1). At T0, the presence of 
Ag-NP
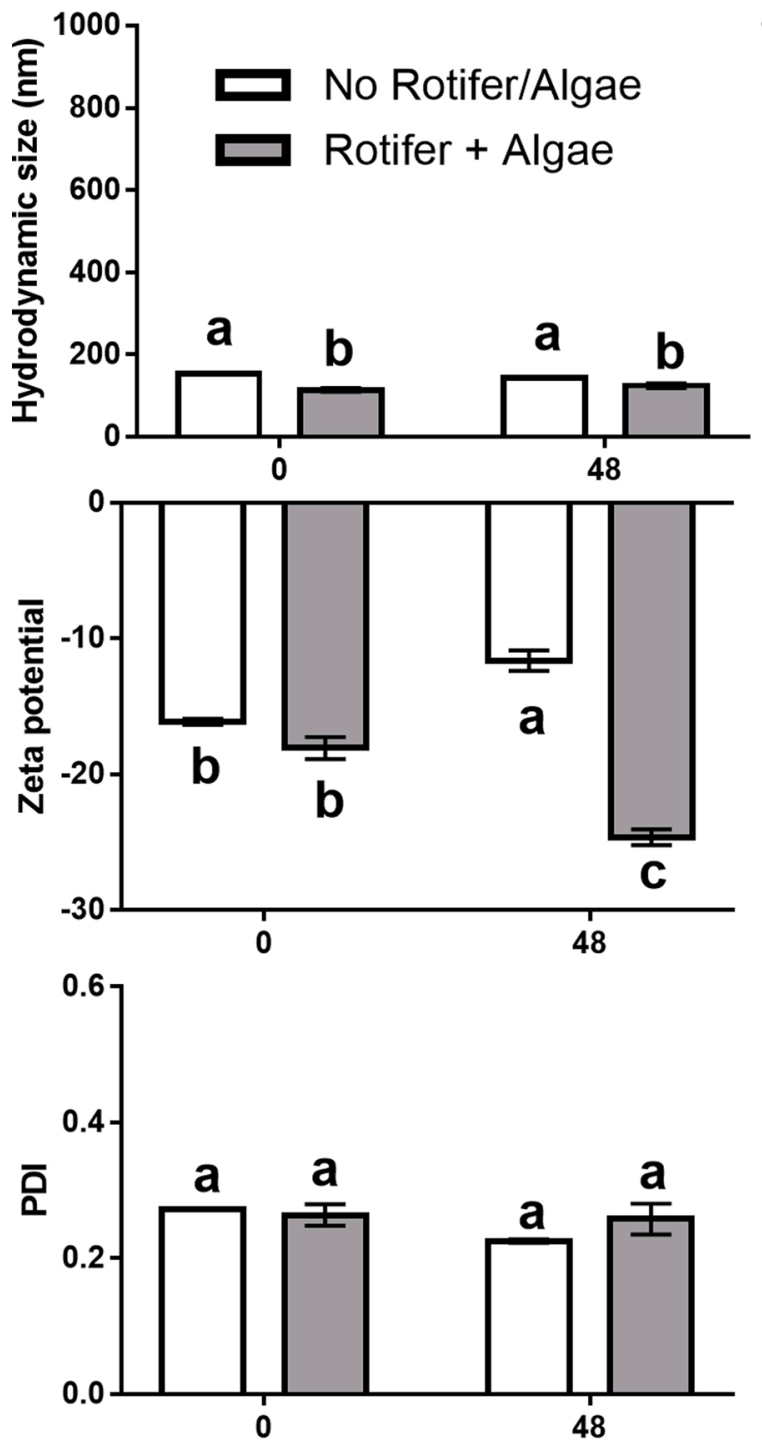

Time (h)
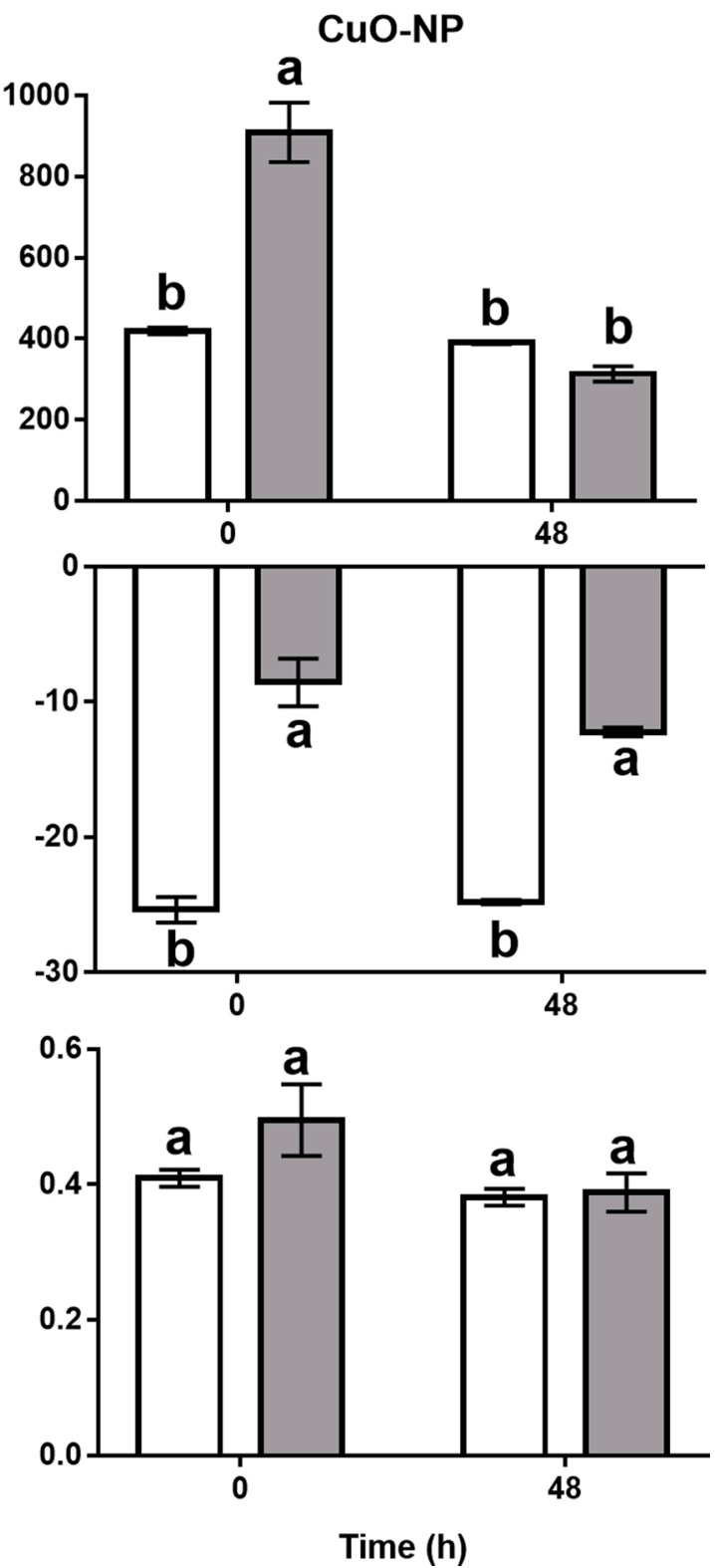

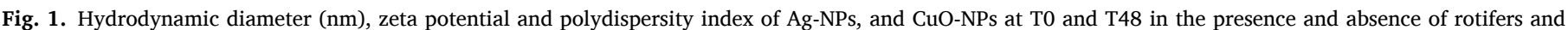

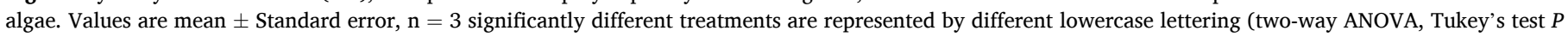
$<0.05)$.

organisms did not change the zeta potential of Ag-NPs ( $P>0.05$; Fig. 1 ), but at T48, a clear decrease in zeta potential was observed (from - 11.6 to $-25.4, P<0.05$; Fig. 1). In the absence of organisms, the zeta potential at T48 was higher than at T0 $(P<0.05 ;$ Fig. 1$)$. The PDI of Ag-NPs showed no significant differences in any experimental conditions (two-away ANOVA, $P>0.05$; Fig. 1).

The exposure time and the presence of organisms had a significant effect on HDD of CuO-NPs (two-way ANOVA, $P<0.05$; Fig. 1). At T0, the presence of rotifers and algae resulted in a significant increase in HDD of CuO-NPs (from 419.7-909.5 nm, $P<0.05$; Fig. 1), but the presence of rotifers and algae did not affect the HDD of NPs at T48 $(P>$ 0.05 ; Fig. 1). The zeta potential of CuO-NPs was affected by the presence of the organisms (two-way ANOVA, $P<0.05$; Fig. 1 ) but not by the exposure time $(P>0.05)$. The presence of rotifers and algae increased the zeta potential of CuO-NPs at T0 (from -25.4 to -8.6, $P<0.05$ ) and at T48 (from -24.8 to $-12.2, P<0.05$; Fig. 1). The PDI of CuO-NPs did not change under the experimental conditions (two-way ANOVA, $P>0.05$; Fig. 1).
Metal dissolution was higher for Ag-NPs than CuO-NPs. At T0 and in the absence of organisms, dissolution of $\mathrm{Ag}^{+}$from Ag-NPs was $26.3 \%$ (T0 total Ag $=496.5 \pm 2.5 \mu \mathrm{g} \mathrm{L}^{-1}$, T0 dissolved Ag $=130.6 \pm 2.2 \mu \mathrm{g} \mathrm{L}^{-1}$; Fig S5). The presence of organisms dropped the total amount of silver to $35.4 \%$ and the amount of dissolved $\mathrm{Ag}^{+}$to $2.4 \%$ (T0 total $\mathrm{Ag}=176.0 \pm$ $11.5 \mu \mathrm{g} \mathrm{L}{ }^{-1}$, T0 dissolved $\mathrm{Ag}=11.9 \pm 0.6 \mu \mathrm{g} \mathrm{L}{ }^{-1}$; Fig S5). At T48 and in the absence of organisms, dissolution of $\mathrm{Ag}^{+}$from Ag-NPs was $29.4 \%$ (T48 total $\mathrm{Ag}=498.2 \pm 1.9 \mu \mathrm{g} \mathrm{L}^{-1}, \mathrm{~T} 48$ dissolved $\mathrm{Ag}=146.0 \pm 6.6 \mu \mathrm{g}$ $\mathrm{L}^{-1}$; Fig S5). The presence of organisms dropped the total amount of $\mathrm{Ag}$ to $48.9 \%$ and the amount of dissolved $\mathrm{Ag}^{+}$to $4.4 \%$ (T48 total $\mathrm{Ag}=$ $242.9 \pm 8.5 \mu \mathrm{g} \mathrm{L}^{-1}, \mathrm{~T} 48$ dissolved $\mathrm{Ag}=22.1 \pm 0.2 \mu \mathrm{g} \mathrm{L}^{-1}$; Fig S5).

At T0 and in the absence of organisms, the dissolution of $\mathrm{Cu}^{2+}$ from CuO-NPs was $1.2 \%$ (T0 total $\mathrm{Cu}=1879.2 \pm 95.2 \mu \mathrm{g} \mathrm{L}{ }^{-1}$, T0 dissolved $\mathrm{Cu}=22.2 \pm 0.7 \mu \mathrm{g} \mathrm{L}^{-1}$; Fig S5). The presence of organisms dropped the total amount of $\mathrm{Cu}$ to $51.3 \%$ and the amount of dissolved $\mathrm{Cu}^{2+}$ to $0.8 \%$ (T0 total $\mathrm{Cu}=964.3 \pm 52.7 \mu \mathrm{g} \mathrm{L}^{-1}$, T0 dissolved $\mathrm{Cu}=14.9 \pm 0.2 \mu \mathrm{g} \mathrm{L}^{-1}$; Fig S5). At T48 and in the absence of organisms, dissolution of $\mathrm{Cu}^{2+}$ from CuO-NPs was $1.0 \%$ (T48 total $\mathrm{Cu}=1815.2 \pm 114.9 \mu \mathrm{g} \mathrm{L}{ }^{-1}$, T0 dissolved 
$\mathrm{Cu}=18.3 \pm 0.4 \mu \mathrm{g} \mathrm{L}^{-1}$; Fig S5). The presence of organisms dropped the total amount of $\mathrm{Cu}$ to $33.1 \%$ and the amount of dissolved $\mathrm{Cu}^{2+}$ to $0.6 \%$ ( $\mathrm{T} 48$ total $\mathrm{Cu}=622.2 \pm 27.6 \mu \mathrm{g} \mathrm{L}{ }^{-1}$, T0 dissolved $\mathrm{Cu}=10.8 \pm 0.6 \mu \mathrm{g}$ $\mathrm{L}^{-1}$; Fig S5).

\subsection{Effects of metal nanoparticles and metal ions on rotifer mortality}

Both Ag-NPs and CuO-NPs caused mortality of B. calyciflorus. In the case of Ag-NPs, the LOEC was $12.8 \mu \mathrm{g} \mathrm{L}^{-1}$ and $100 \%$ mortality was observed at $80 \mu \mathrm{g} \mathrm{L}^{-1}$ (Fig. S3). The LOEC for CuO-NPs was $625 \mu \mathrm{g} \mathrm{L}^{-1}$ (Fig. S3) and $100 \%$ mortality was obtained at $1250 \mu \mathrm{L} \mathrm{L}^{-1}$. The $50 \%$ lethal effect concentrations of metal ions to rotifers $\left(\mathrm{Ag}^{+}, \mathrm{EC}_{50}=4.3\right.$ (3.5-4.9) $\mu \mathrm{g} \mathrm{L}^{-1}$; LOEC $=5.1 \mu \mathrm{g} \mathrm{L}^{-1} ; \mathrm{Cu}^{2+}, \mathrm{EC}_{50}=15.2(14.7-15.7) \mu \mathrm{g}$ $\mathrm{L}^{-1}$, LOEC $=17.8 \mu \mathrm{g} \mathrm{L}^{-1}$, Table 1, Fig. S3) were lower than those of respective NPs (Ag-NPs, $\mathrm{EC}_{50}=17.5(14.3-21.9) \mu \mathrm{g} \mathrm{L}{ }^{-1}$; LOEC $=12.8$ $\mu \mathrm{g} \mathrm{L}^{-1}$; CuO-NPs $\mathrm{EC}_{50}=600.9(525.2-700.4) \mu \mathrm{g} \mathrm{L}^{-1}$, LOEC $=625 \mu \mathrm{g}$ $\mathrm{L}^{-1}$, Table 1, Fig. S3).

\subsection{Effects of metal nanoparticles and metal ions on population growth} rate

The exposure of rotifers to Ag-NPs significantly affected the population growth rate; the LOEC of Ag-NPs was $6.25 \mu \mathrm{g} \mathrm{L} \mathrm{L}^{-1}$ and $100 \%$ of growth inhibition was obtained at $50 \mu \mathrm{g} \mathrm{L}^{-1}$ (Fig. 2). LOEC values for Ag-NPs and $\mathrm{Ag}^{+}$were similar $\left(6.25 \mu \mathrm{g} \mathrm{L}^{-1}\right.$, Fig. 2). The exposure to CuONPs significantly inhibited population growth rate at a LOEC of $62.5 \mu \mathrm{g}$ $\mathrm{L}^{-1}$, while $\mathrm{Cu}^{2+}$ had a LOEC of $50 \mu \mathrm{g} \mathrm{L}^{-1}$ (Fig. 2). The concentrations inhibiting population growth rate by $50 \%$ were lower for ionic forms than for their nanoparticulate forms (CuO-NPs EC ${ }_{50}=83.8$ (65.9-101.7) $\mu \mathrm{g} \mathrm{L}^{-1}$ vs $\mathrm{Cu}^{2+} \mathrm{EC}_{50}=50.3(43.9-56.8) \mu \mathrm{g} \mathrm{L}^{-1}$, and Ag-NPs $\mathrm{EC}_{50}=8.7$ (6.2-11.2) $\mu \mathrm{g} \mathrm{L}^{-1} \mathrm{vs} \mathrm{Ag}^{+} \mathrm{EC}_{50}=6$ (5.1-6.9) $\mu \mathrm{g} \mathrm{L}^{-1}$, Table 1).

\subsection{Reactive oxygen species accumulation and plasma membrane damage}

The $48 \mathrm{~h}$ exposure of rotifers to $\mathrm{EC}_{10}$ of each contaminant led to noticeable accumulation of reactive oxygen species (ROS) and damage of plasma membrane comparing to control organisms (Fig. 3). Plasma membrane damage was very pronounced and similar between the four tested contaminants, but ROS accumulation varied with the contaminant (Fig. 3). $\mathrm{Cu}^{2+}$ ion led to a higher level of ROS accumulation than CuO-NPs, while both Ag forms led to similar levels of ROS accumulation. The accumulation of ROS and the plasma membrane damage increased with the increase in concentrations of NPs and metal ions (not shown).

Table 1

Effective concentrations for mortality and population growth rate for Ag-NPs, CuO-NPs, $\mathrm{Ag}^{+}$and $\mathrm{Cu}^{2+}$. In brackets are indicated $95 \%$ confidence limits.

\begin{tabular}{|c|c|c|c|c|}
\hline Contaminant & Endpoint & $\begin{array}{l}\text { LOEC } \\
\left(\mu \mathrm{g} \mathrm{L}^{-1}\right)\end{array}$ & $\mathrm{EC}_{10}\left(\mu \mathrm{g} \mathrm{L}^{-1}\right)$ & $\mathrm{EC}_{50}\left(\mu \mathrm{g} \mathrm{L}^{-1}\right)$ \\
\hline \multirow{2}{*}{ Ag-NPs } & Mortality & 12.8 & $5.8(1.8-8.8)$ & $\begin{array}{l}17.5 \\
(14.3-21.9)\end{array}$ \\
\hline & $\begin{array}{l}\text { Population } \\
\text { growth rate }\end{array}$ & 6.25 & $1.7(0.6-2.9)$ & $8.7(6.2-11.2)$ \\
\hline \multirow[b]{2}{*}{$\mathbf{A g}^{+}$} & Mortality & 5.12 & $2.9(1.1-3.7)$ & $4.3(3.5-4.9)$ \\
\hline & $\begin{array}{l}\text { Population } \\
\text { growth rate }\end{array}$ & 6.25 & $4.5(0-9.2)$ & $6.0(5.1-6.9)$ \\
\hline \multirow{2}{*}{ CuO-NPs } & Mortality & 625 & $\begin{array}{l}198.2 \\
(112.9-267.6)\end{array}$ & $\begin{array}{l}600.9 \\
(525.2-700.4)\end{array}$ \\
\hline & $\begin{array}{l}\text { Population } \\
\text { growth rate }\end{array}$ & 62.5 & $\begin{array}{l}46.9 \\
(27.6-66.1)\end{array}$ & $\begin{array}{l}83.8 \\
(65.9-101.7)\end{array}$ \\
\hline \multirow{2}{*}{$\mathrm{Cu}^{2+}$} & Mortality & 15.22 & $\begin{array}{l}12.8 \\
(11.9-13.5)\end{array}$ & $\begin{array}{l}15.2 \\
(14.7-15.7)\end{array}$ \\
\hline & $\begin{array}{l}\text { Population } \\
\text { growth rate }\end{array}$ & 50 & $35(8.0-62.0)$ & $\begin{array}{l}50.3 \\
(43.9-56.8)\end{array}$ \\
\hline
\end{tabular}

\subsection{Transgenerational effects of metal nanoparticles and metal ions}

In the control, the population growth rate of rotifers was higher than $0.55 \mathrm{~d}^{-1}$ and no evidence of parental mortality. The exposure to $\mathrm{EC}_{50}$ of each contaminant led to a significant inhibition $(P<0.05)$ in the population growth rate (Fig. 4). Mortality was only observed under $\mathrm{Cu}^{2+}$ exposure showing 1 death parent. At $\mathrm{F} 1$, the population growth rate was significantly inhibited $(P<0.05)$ by exposure to Ag-NPs and $\mathrm{Cu}^{2+}$. Mortality at F1 was observed after exposure to $\mathrm{Cu}^{2+}$ and Ag-NPs, and in rotifers pre-exposed to $\mathrm{Ag}^{+}$. At F2 generation, only the rotifers exposed to Ag-NPs had a decreased population growth rate. Parental mortality was low but still occurred in rotifers under exposure to $\mathrm{Cu}^{2+}$ and in those pre-exposed to Ag-NPs. At F3 and F4 generations, the contaminants did not affect the rotifer growth rates. However, parental mortality occurred in rotifers at $\mathrm{F} 3$ under $\mathrm{Cu}^{2+}$ exposure, and at $\mathrm{F} 4$ under exposure to $\mathrm{CuO}$ $\mathrm{NPs}$, pre-exposed to Ag-NPs or $\mathrm{Ag}^{+}$. The population growth rate of rotifers pre-exposed to the contaminants from $\mathrm{F} 1$ to $\mathrm{F} 4$ generations did not differ from control (one-way ANOVA, $P<0.05$; Fig. 4).

Although recovery of population growth rate was observed at F3 and $\mathrm{F} 4$, rotifer development delays occurred in at least one replicate per treatment and were intrinsically connected to parental mortality observed (Fig. S4).

At F0 generation, ROS accumulation and plasma membrane damage were clearly visible in all treatments apart from the control (Fig. 5). At F4 generation, ROS accumulation and plasma membrane damage slightly increased after exposure to Ag-NPs and $\mathrm{Ag}^{+}$, while decreased after exposure to $\mathrm{CuO}-\mathrm{NPs}$ and $\mathrm{Cu}^{2+}$. At F4, the rotifers pre-exposed to $\mathrm{Ag}^{+}$and $\mathrm{Cu}^{2+}$ showed ROS accumulation and plasma membrane damage, while the rotifers pre-exposed to Ag-NPs and CuO-NPs showed very faint ROS accumulation and had the least plasma membrane damage (Fig. 5).

\section{Discussion}

This study showed that metal nanoparticles and their ionic forms might be toxic to freshwater populations of $B$. calyciflorus, leading to mortality and reducing population growth rate. Both lethal and sublethal effects of Ag-NPs were more pronounced than those of CuO-NPs (effects on population growth rate: $\mathrm{EC}_{50}=8.7 \mu \mathrm{g} \mathrm{L}^{-1}$ for Ag-NPs vs $83.8 \mu \mathrm{g} \mathrm{L}^{-1}$ for CuO-NPs). An opposite trend was observed for leaf decomposition by aquatic microbes where CuO-NPs had a more pronounced impact than Ag-NPs (Pradhan et al., 2011). Both Ag-NPs and CuO-NPs showed a tendency to be less toxic to rotifers than their respective ionic forms. A less pronounced effect of metal nanoparticles on aquatic organisms compared to their ionic counterparts have been reported (Pradhan et al., 2011; Garner et al., 2015; Batista et al., 2017).

In our study, the rotifers and algae removed a higher amount of AgNPs from the medium when compared to $\mathrm{Ag}^{+}$(Fig. S2), which might have resulted from a higher accumulation and/or adsorption and/or lower release of nanoparticles by the rotifers. A higher $\mathrm{Ag}^{+}$uptake compared to its nanoparticle form was reported by $D$. magna (Ribeiro at al., 2017), which could be due to the uptake of $\mathrm{Ag}^{+}$by cells through ion transporters (Luoma, 2008), increasing the entry of $\mathrm{Ag}^{+}$more than of Ag-NPs. On the other hand, the uptake of metal NPs has been related to endocytosis processes (Pan and Wang, 2004; Ribeiro et al., 2017) that can be influenced by hydrodynamic size of nanoparticles. Considering the characteristics of $\mathrm{Ag}^{+}$and Ag-NPs, a lower uptake rate of Ag-NPs associated with a lower elimination rate of Ag-NPs might have been responsible for the lower amount of silver in media in the presence of the organisms. This pattern was also observed in D. magna, in which depuration of Ag-NPs was lower than that of $\mathrm{Ag}^{+}$due to their larger size (Ribeiro et al., 2017). In our study, the presence of rotifers and algae led to a reduction in the hydrodynamic size of Ag-NPs in the medium, possibly due to accumulation and/or adsorption of larger particles to the organisms; this was further supported by the decrease in zeta potential of Ag-NPs in the presence of the organisms after $48 \mathrm{~h}$ of exposure (-11.6 
A

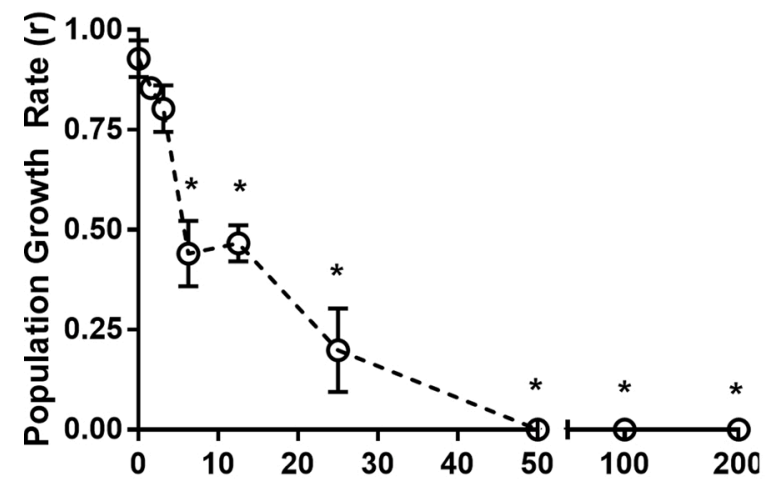

C

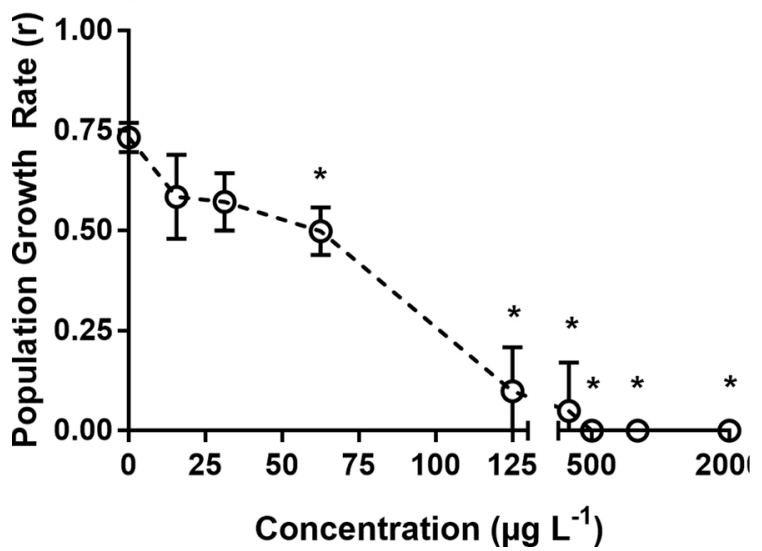

B

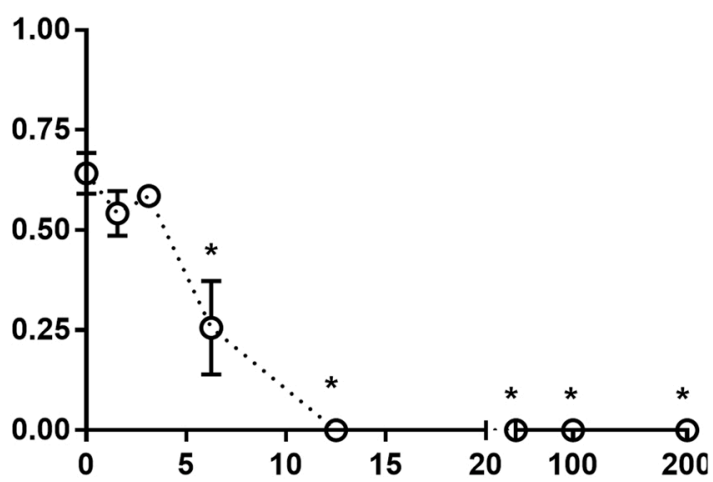

D

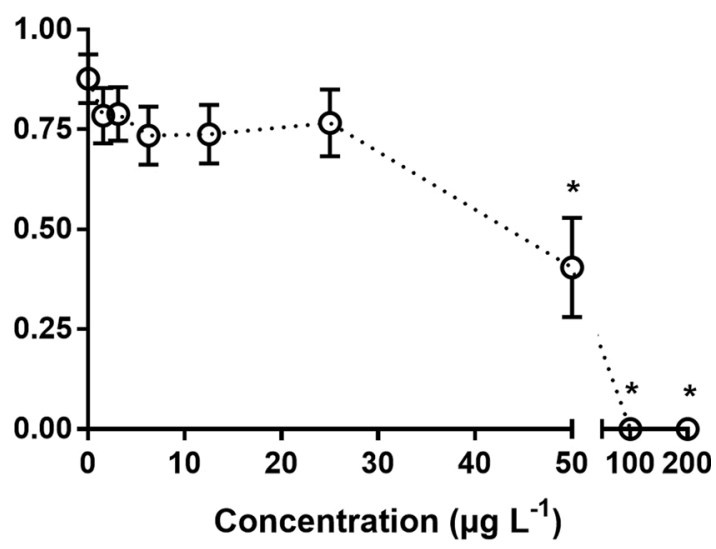

Fig. 2. Population growth rate of B. calyciflorus exposed to increasing concentrations of: A) Ag-NPs, B) $\left.\mathrm{Ag}^{+}, \mathrm{C}\right) \mathrm{CuO}-\mathrm{NPs}$ and D) $\mathrm{Cu}^{2+}$. Values are mean \pm standard error of the mean, $\mathrm{n}=8$. * significantly different from the control (One-way ANOVA, Dunnet's test $P \leq 0.05$ ).

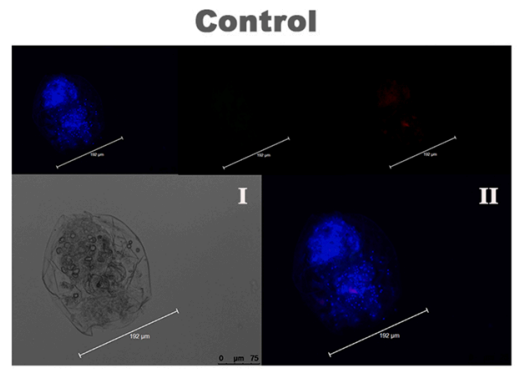

CUO-NP EC10

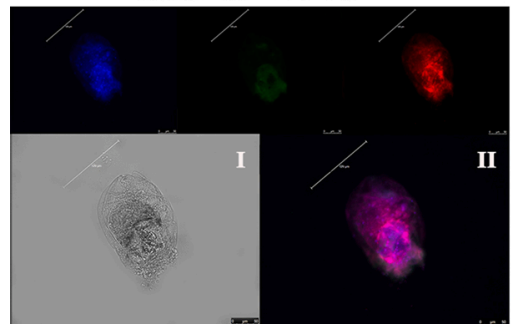

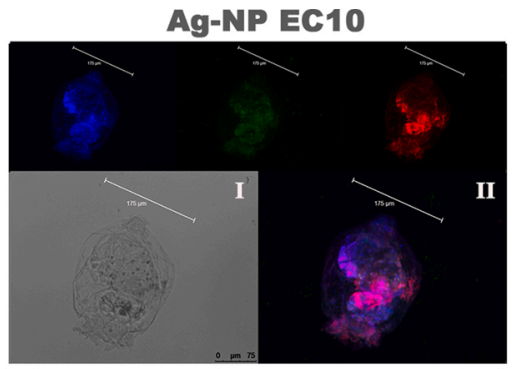

$\mathrm{Cu}^{2+} \mathrm{EC} 10$

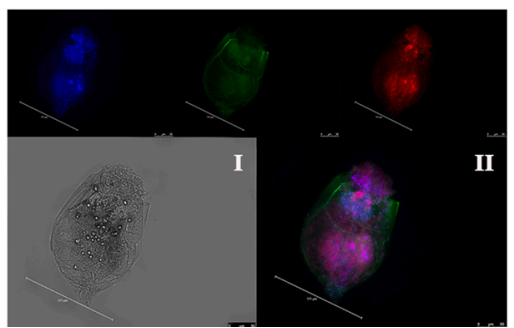

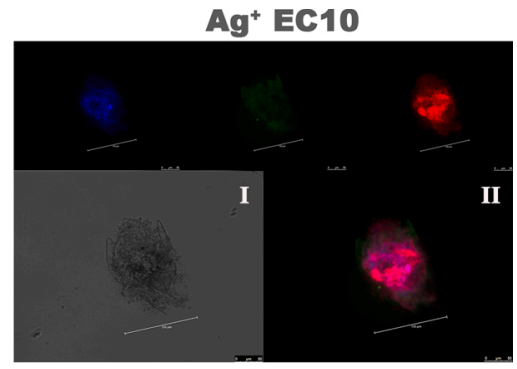

II

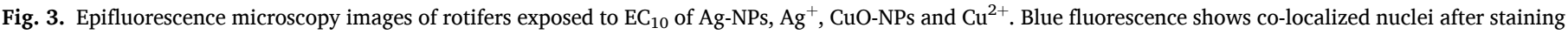

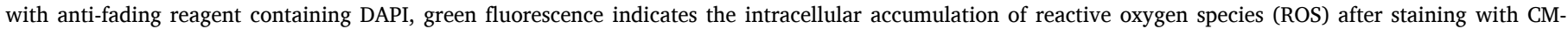

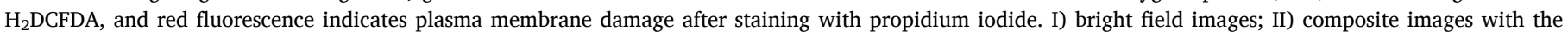
3 stains.

$\mathrm{mV}$ to $-24.6 \mathrm{mV}$ ). If rotifers accumulate and/or adsorb NPs, the possibility of trophic transfer of Ag-NPs cannot be discarded. When looking at $\mathrm{EC}$ values for the effects of $\mathrm{Ag}$-NPs on B. calyciflorus $\left(\mathrm{EC}_{10}=5.8 \mu \mathrm{g} \mathrm{L}^{-1}\right)$ compared to the detected concentrations in the environment (0.3-6.6 ng $\mathrm{L}^{-1}$; Peters et al., 2018), an assumption of low environmental risk might be assumed. However, a worst scenario can be envisaged when considering the predicted environmental concentrations that are much closer to EC values (up to $0.6 \mu \mathrm{g} \mathrm{L}^{-1}$; Musee, 2011). Nevertheless, the higher accumulation in organisms and possible release of Ag ions indicate an unpredictable contribution of Ag-NPs to the increase in total 

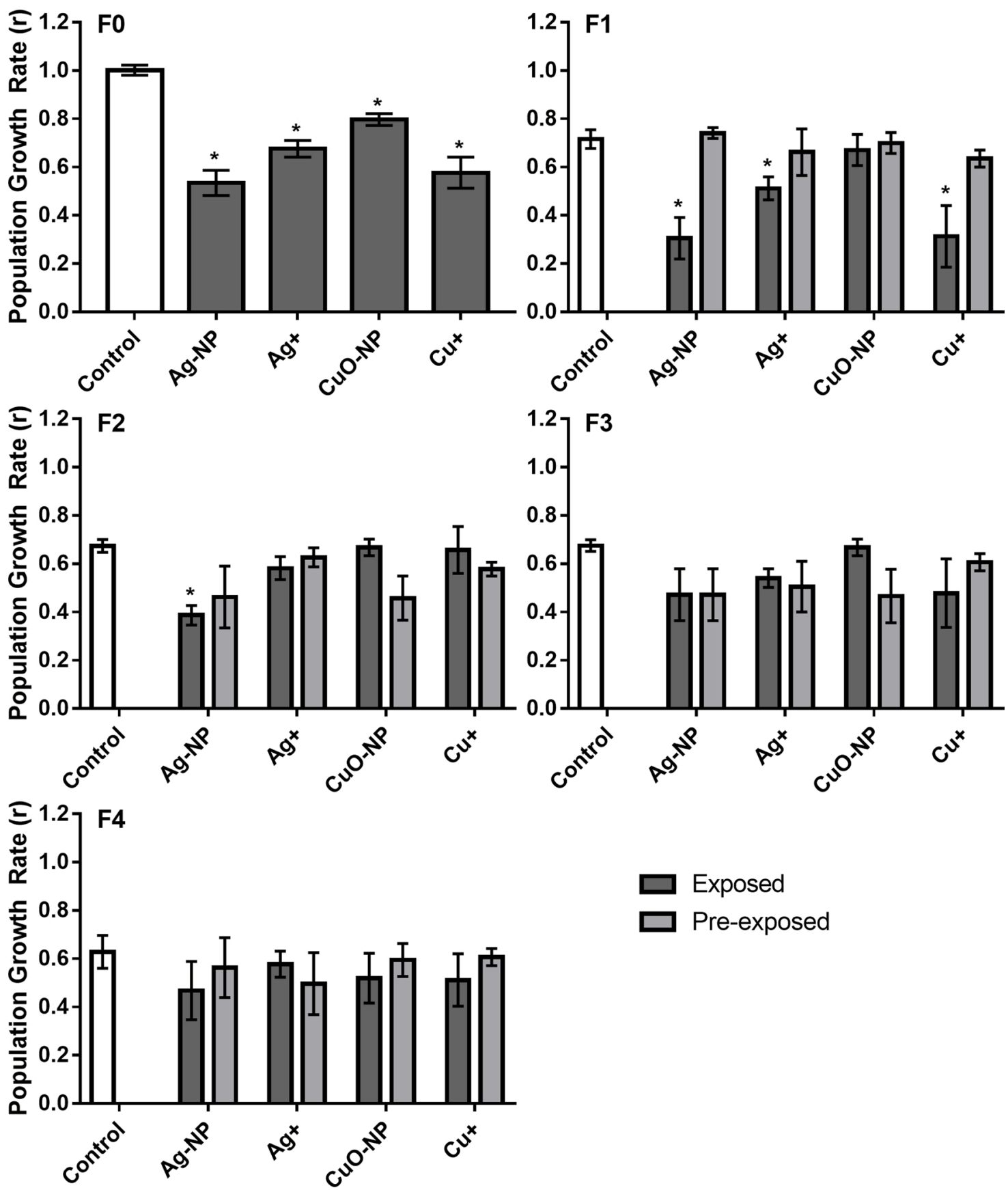

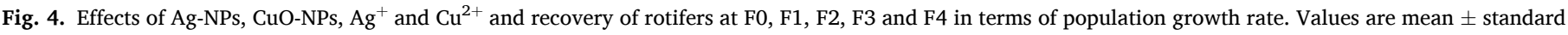
error, $\mathrm{n}=8$. * statistical different from the control (one-way ANOVA; $P \leq 0.05$ ).

silver in aquatic environments with potential impacts in the longer term.

In our study, CuO-NPs were less toxic than $\mathrm{Cu}^{2+}$ to rotifers as depicted by the effects on mortality and population growth rate. Our results are in alignment with those from $D$. magna showing stronger effects of $\mathrm{Cu}^{2+}\left(\mathrm{EC}_{50}=22 \mu \mathrm{g} \mathrm{L}^{-1}\right)$ than of CuO-NPs $\left(\mathrm{EC}_{50}=1041 \mu \mathrm{g} \mathrm{L}^{-1}\right)$ on reproduction (Adam et al., 2015), and are in alignment with the general trend observed through species sensitivity distribution of CuO-NPs and their ionic forms for aquatic organisms (Garner et al., 2015). The entry of $\mathrm{Cu}^{2+}$ into cells through the ion transporters (Luoma, 2008) may contribute to explain the high toxicity of metal ions. Although $\mathrm{Cu}^{2+}$ released from CuO-NPs might contribute to the overall CuO-NPs toxicity, dissolution data showed that contribution of ionic $\mathrm{Cu}$ was low, in our study. Agglomeration and particle stability are postulated to interfere with the uptake, availability and depuration of
CuO-NPs from organisms and, therefore, affecting toxicity (Adam et al., 2015). Indeed, this was observed in our study, where aggregation of CuO-NPs increased along time. This can be the result of interactions between components of the medium and the nanoparticles and/or processes of self-agglomeration (Pradhan et al., 2014), explaining the increase in the hydrodynamic size and the decrease in stability. Surprisingly, higher accumulation of $\mathrm{Cu}$ in rotifers occurred after exposure to $\mathrm{CuO}-\mathrm{NPs}$ than to $\mathrm{Cu}^{2+}$ (Fig. S2), suggesting that rotifers can uptake CuO-NPs at a higher rate than $\mathrm{Cu}^{2+}$ and/or showing lower elimination rate as discussed for Ag-NPs. A similar trend was found in D. magna, in which copper body burden was 2.8-42 times higher under exposure to CuO-NPs than to $\mathrm{Cu}^{2+}$ (Muna et al., 2017). Despite the apparent higher removal of CuO-NPs by rotifers and algae, the toxicity was lower than the one exhibited by $\mathrm{Cu}^{2+}$. Comparison of CuO-NPs EC values on 
Control F0

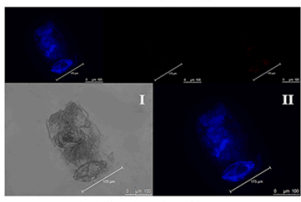

Control F4

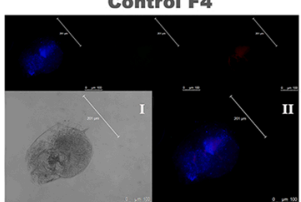

Control F4

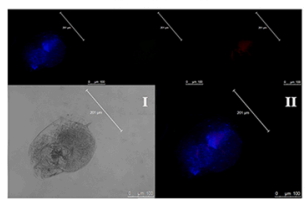

Ag-NP F0 EC50

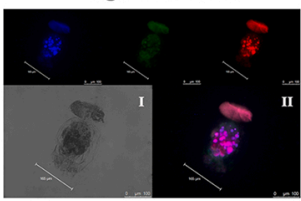

Ag-NP F4 EC50

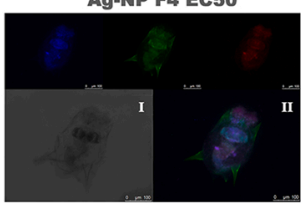

Ag-NP pre-exposed F4 EC50

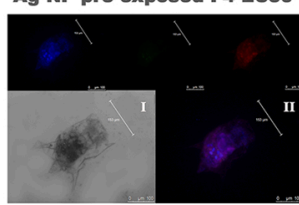

$\mathrm{Ag}^{+}$F0 EC50

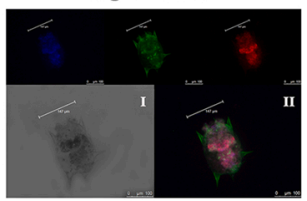

$\mathrm{Ag}^{+}$F4 EC50

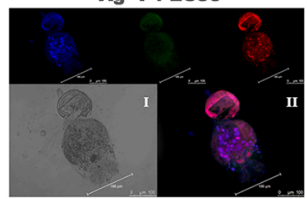

$\mathrm{Ag}^{+}$pre-exposed F4 EC50

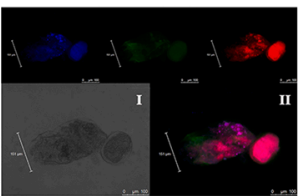

CuO-NP FO EC50

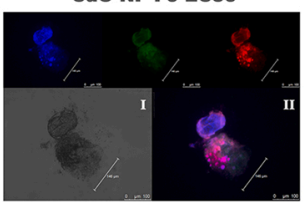

CuO-NP F4 EC50

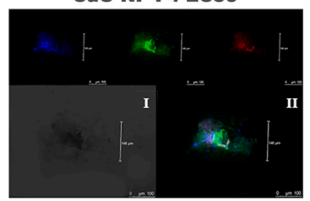

CuO-NP pre-exposed F4 EC50

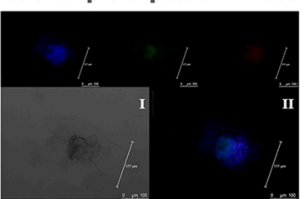

$\mathrm{Cu}^{2+}$ FO EC50

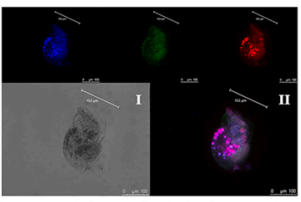

$\mathrm{Cu}^{2+} \mathrm{F} 4 \mathrm{EC} 50$

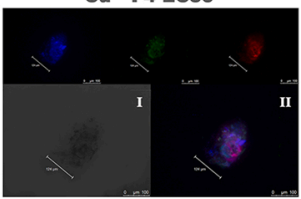

$\mathrm{Cu}^{2+}$ pre-exposed F4 EC50

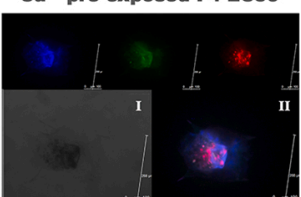

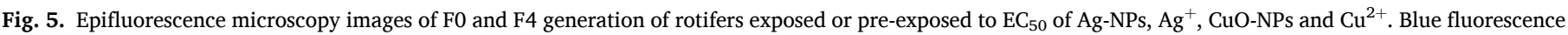

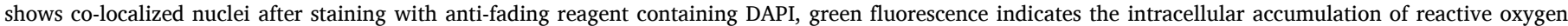

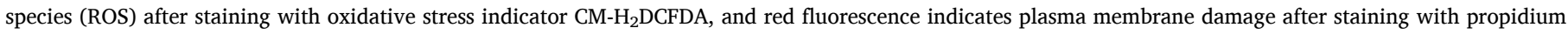
iodide. I) bright field images; II) composite images with all 3 stains.

B. calyciflorus (population growth rate $\mathrm{EC}_{10}=46.9 \mu \mathrm{g} \mathrm{L}^{-1}$ ) to environmental concentrations is difficult because few data are available. However, in industrial wastewaters CuO-NPs can exceed $100 \mathrm{mg} \mathrm{L}^{-1}$ (Huang et al., 2006), making our conclusions relevant.

There is still a controversy on the origin of NPs toxicity: some studies indicate that the toxicity of CuO-NPs is the consequence of the dissolution of $\mathrm{Cu}^{2+}$ from the nanoparticles (Jo et al., 2012; Adam et al., 2015), while others claim the occurrence of nanoparticle-specific effects (Kasemets et al., 2009; Manusadžianas et al., 2012). The same is applicable to Ag-NPs where some studies show a similar toxicity mechanism to $\mathrm{Ag}^{+}$through the disruption of Na regulation (Kwok et al., 2016), while others show that due to low dissolution of metal ions from the Ag-NPs, the toxicity is attributed mainly to their nano form (Batista et al., 2017; Clark et al., 2018). The latter hypothesis is supported by results from aquatic microbes, where proteomic profiles of microbes exposed to Ag-NPs and $\mathrm{Ag}^{+}$largely differ, suggesting distinct cellular targets and mechanisms of toxicity (Barros et al., 2020). In our study, dissolution of $\mathrm{Ag}$ ions from Ag-NPs in the medium without organisms was low and was even lower in the presence of organisms, reaching concentrations near to $\mathrm{Ag}^{+} \mathrm{EC}_{50}$ values. This suggests that $\mathrm{Ag}^{+}$released from Ag-NPs cannot explain the observed toxicity, so nanoparticle-specific effects might have occurred. When it comes to CuO-NPs, dissolved $\mathrm{Cu}^{2+}$ (c.a. 1\% of total copper dissolved in medium) was even lower than $\mathrm{Ag}^{+}$. Therefore, dissolved $\mathrm{Cu}^{2+}$ appeared to have a minor role in the observed toxicity.

In our study, the toxicity of all metal forms (Ag-NP, $\mathrm{Ag}^{+}, \mathrm{CuO}-\mathrm{NP}$ and $\mathrm{Cu}^{2+}$ ) was associated with ROS accumulation and plasma membrane damage. The connection between $\mathrm{Ag}^{+}$and Ag-NPs toxicity and their ability to induce the accumulation of ROS has been widely reported (Kwok et al., 2016; AshaRani et al., 2009; Dąbrowska-Bouta et al., 2019; Khan et al., 2019), including in human cell lines, in which the toxicity of Ag-NPs has been mainly attributed to the induction of oxidative stress, protein and DNA damage, and apoptotic death (Arora et al., 2008; Hsin et al., 2008; Kim et al., 2009). Similarly, many studies claim a similar connection for CuO-NPs (Karlsson et al., 2009; Petersen and Nelson, 2010; Chang et al., 2012; Pradhan et al., 2015). This hypothesis was supported by our study with a strong accumulation of ROS and visible membrane damage at the $\mathrm{EC}_{10}$ concentration of both nanoparticles. Accumulation of ROS was more pronounced for $\mathrm{Cu}^{2+}$ than CuO-NPs, regardless the higher retention of CuO-NPs by rotifers, further suggesting that CuO-NPs had a specific toxicity pathway independent of the dissolution of $\mathrm{Cu}^{2+}$ and its internalization by rotifers.

The exposure of rotifers to $\mathrm{Ag}-\mathrm{NPs}$ and $\mathrm{Ag}^{+}$across generations showed a recovery of rotifer population growth rate. Specifically, longterm exposure to $\mathrm{Ag}^{+}$led to the recovery at the $\mathrm{F} 1$ generation, while the recovery from Ag-NPs only occurred at the F3 generation. Although the population growth rate recovered, a delay in the reproduction was observed, probably indicating that the animal fitness was affected. A similar result was found in C. elegans with multigenerational exposure to sub-lethal concentrations of Ag-NPs resulting in a higher tolerance revealed by fertility and fecundity, but a delay in development and somatic growth (Rossbach et al., 2019). Moreover, rotifer populations continuously exposed to $\mathrm{Ag}$-NPs and $\mathrm{Ag}^{+}$were under stress, as shown by ROS accumulation and plasma membrane damage in $\mathrm{F} 4$ populations. Therefore, we can infer that rotifer offspring resulting from the contaminated F0 generation exhibited signs of stress even after four generations. However, F4 rotifers pre-exposed to Ag-NPs and then released from the contaminant showed signs of recovery with lower accumulation of ROS and lower level of plasma membrane damage. In our study, the population growth rate recovery might be related to the selection of more resistant genotypes rather than a recovery of the animal fitness. Similarly, in C. elegans, $\mathrm{Ag}^{+}$and Ag-NPs caused differences in size and lifespan in the F2 generation, and effects persisted in the pre-exposed generations after the removal of contaminants (Schultz et al., 2016). On the other hand, Mendes et al. (2018) showed silver multigeneration exposure of Folsomia candida resulted in increased effects after 4 generations. The removal from contaminants led to reproduction recovery in terms of number of juveniles, but arthropods had a smaller size than those of control (Mendes et al., 2018). These results support the idea that effects caused by $\mathrm{Ag}-\mathrm{NPs}$ and $\mathrm{Ag}^{+}$may persist in different organisms along time.

The toxicity of CuO-NPs, assessed by $\mathrm{EC}_{50}$, slightly decreased along the rotifer generations continuously exposed to the toxicant; this can be explained by the low stability of the nanoparticles with time that might have influenced their concentration and bioavailability. A full recovery in the population growth rate was observed for CuO-NPs at $\mathrm{F} 1$ and $\mathrm{Cu}^{2+}$ at F2 and further generations. The rotifers, released from the contaminants at F1, recovered regardless the $\mathrm{Cu}$ form. As observed for Ag-NPs, we found a delay in reproduction even when population growth rate had already recovered. Intracellular ROS accumulation and plasma membrane damage was still observed in the rotifers exposed either to $\mathrm{CuO}$ $\mathrm{NPs}$ or $\mathrm{Cu}^{2+}$ till the $\mathrm{F} 4$ generation even though population growth rate 
recovered. However, the rotifers pre-exposed to CuO-NPs showed signs of recovery at F4, with lower accumulation of ROS and less plasma membrane damage. CuO-NPs seemed to show a less pronounced transgenerational effects than $\mathrm{Cu}^{2+}$, supporting different mechanisms of toxicity. Yu et al. (2013) showed clear transgenerational effects of metals $(\mathrm{Cu}, \mathrm{Cd}, \mathrm{Pb}$ and $\mathrm{Zn})$ in $C$. elegans, with a greater impact on the behaviour and growth inhibition for the progeny at F1 generation. This suggests that the parental exposure can increase the sensitivity of future generations to toxicants. Multigenerational effects of CuO-NMs and $\mathrm{CuCl}_{2}$ on the soil invertebrate Enchytraeus crypticus showed no change in sensitivity to $\mathrm{CuO}-\mathrm{NMs}$ but increased toxicity at $\mathrm{EC}_{10}$, with organisms recovering from contamination once transferred to clean medium (Bicho et al., 2017), as observed in our study. Meanwhile, the multigeneration exposure to $\mathrm{CuCl}_{2}$ reduced the toxic effects at $\mathrm{EC}_{10}$ and $\mathrm{EC}_{50}$ concentrations but the transfer to clean medium increased the effects (Bicho et al., 2017). These studies support the idea that different mechanisms of action are responsible for the toxicity of CuO-NPs and $\mathrm{Cu}^{2+}$ and also show that different endpoints and populations may have different responses across generations, with some populations showing recovery through generations and others an increased sensitivity.

\section{Conclusions}

The toxicity of metal ions and metal NPs towards the rotifer B. calyciflorus was translated in mortality and inhibition of population growth rate. Dissolution data showed that the effects of metal NPs were nanoparticle specific with CuO-NPs showing very low dissolution in our study. Oxidative stress was observed in rotifers exposed to low effect concentrations (e.g., $\mathrm{EC}_{10}$ ) of both ions and NPs. Contrarily to our predictions, rotifers exposed to ions and NPs were able to fully recover its population growth rate at F3, but, in certain cases, there was a delay in their reproduction. This can be partially explained by ROS accumulation and plasma membrane damage. Rotifer populations showed signs of resilience to both metal ions and NPs, but the higher accumulation of metal NPs than metal ions might be a risk in the longer term. Overall, our study represents a step forward in exploring toxicant effects beyond F0 generation to better assess the risk of metallic nanoparticles and their ionic counterparts in freshwaters.

\section{CRediT authorship contribution statement}

Nuno Martins: Conceptualization, Methodology, Investigation, Data curation, Formal analysis, Writing - original draft. Arunava Pradhan: Conceptualization, Methodology, Supervision, Investigation, Writing - review \& editing. Cláudia Pascoal: Conceptualization, Methodology, Supervision, Writing - review \& editing. Fernanda Cássio: Conceptualization, Methodology, Supervision, Funding acquisition, Writing - review \& editing.

\section{Declaration of Competing Interest}

The authors declare that they have no known competing financial interests or personal relationships that could have appeared to influence the work reported in this paper.

\section{Acknowledgments}

This work was supported by the strategic programme UID/BIA/ 04050/2019 and the Emergemix project (PTDC/BIABMA/30922/2017) funded by national funds through the Portuguese Foundation for Science and Technology (FCT) I.P. and by the European Regional Development Fund (ERDF) through the COMPETE2020 - Programa Operacional Competitividade e Internacionalização. Nuno Martins (UMINHO/BD/ 24/2016) was also supported by The Doctoral Program in Applied and Environmental Microbiology - NORTE-08-5369-FSE-000060 funded by NORTE2020 through the European Social Fund.

\section{Appendix A. Supplementary data}

Supplementary material related to this article can be found, in the online version, at doi:https://doi.org/10.1016/j.aquatox.2020.105652.

\section{References}

Adam, N., Vakurov, A., Knapen, D., Blust, R., 2015. The chronic toxicity of CuO nanoparticles and copper salt to Daphnia magna. J. Hazard. Mater. 283, 416-422. https://doi.org/10.1016/j.jhazmat.2014.09.037.

Arora, S., Jain, J., Rajwade, J.M., Paknikar, K.M., 2008. Cellular responses induced by silver nanoparticles: in vitro studies. Toxicol. Lett. 179, 93-100. https://doi.org/ 10.1016/j.toxlet.2008.04.009.

Asharani, P.V., Low, G., Mun, K., Hande, M.P., Valiyaveettil, S., 2009. Cytotoxicity and genotoxicity of silver. ACS Nano 3, 279-290. https://doi.org/10.1021/nn800596w.

Baker, T.R., Peterson, R.E., Heideman, W., 2014. Using zebrafish as a model system for studying the transgenerational effects of dioxin. Toxicol. Sci. 138, 403-411. https:// doi.org/10.1093/toxsci/kfu006.

Barnett, B.P., Arepally, A., Karmarkar, P.V., Qian, D., Gilson, W.D., Walczak, P., Howland, V., Lawler, L., Lauzon, C., Stuber, M., Kraitchman, D.L., Bulte, J.W.M., 2007. Magnetic resonance-guided, real-time targeted delivery and imaging of magnetocapsules immunoprotecting pancreatic islet cells. Nat. Med. 13, 986-991. https://doi.org/10.1038/nm1581.

Barros, D., Pradhan, A., Pascoal, C., Cássio, F., 2020. Proteomic responses to silver nanoparticles vary with the fungal ecotype. Sci. Total Environ. 704, 135385 https:// doi.org/10.1016/j.scitotenv.2019.135385.

Batista, D., Pascoal, C., Cássio, F., 2017. How do physicochemical properties influence the toxicity of silver nanoparticles on freshwater decomposers of plant litter in streams? Ecotoxicol. Environ. Saf. 140, 148-155. https://doi.org/10.1016/j. ecoenv.2017.02.039.

Bicho, R.C., Santos, F.C.F., Scott-Fordsmand, J.J., Amorim, M.J.B., 2017. Multigenerational effects of copper nanomaterials (CuONMs) are different of those of $\mathrm{CuCl2}$ : Exposure in the soil invertebrate Enchytraeus crypticus. Sci. Rep. 7, 8457. https://doi.org/10.1038/s41598-017-08911-0.

Bondarenko, O., Juganson, K., Ivask, A., Kasemets, K., Mortimer, M., Kahru, A., 2013. Toxicity of Ag, $\mathrm{CuO}$ and $\mathrm{ZnO}$ nanoparticles to selected environmentally relevant test organisms and mammalian cells in vitro: a critical review. Arch. Toxicol. 87 (7), 1181-1200. https://doi.org/10.1007/s00204-013-1079-4.

Capek, I., 2004. Preparation of metal nanoparticles in water-in-oil (w/o) microemulsions. Adv. Colloid Interface Sci. 110, 49-74. https://doi.org/10.1016/j. cis.2004.02.003.

Castro, B.B., Freches, A.R., Rodrigues, M., Nunes, B., Antunes, S.C., 2018. Transgenerational effects of toxicants: an extension of the Daphnia 21-day chronic assay? Arch. Environ. Contam. Toxicol. 74, 616-626. https://doi.org/10.1007/ s00244-018-0507-0.

Chang, Y.N., Zhang, M., Xia, L., Zhang, J., Xing, G., 2012. The toxic effects and mechanisms of $\mathrm{CuO}$ and $\mathrm{ZnO}$ nanoparticles. Materials (Basel). 5, 2850-2871. https://doi.org/10.3390/ma5122850.

Clark, N.J., Shaw, B.J., Handy, R.D., 2018. Low hazard of silver nanoparticles and silver nitrate to the haematopoietic system of rainbow trout. Ecotoxicol. Environ. Saf. 152, 121-131. https://doi.org/10.1016/j.ecoenv.2018.01.030.

Dąbrowska-Bouta, B., Sulkowski, G., Strużyński, W., Strużyńska, L., 2019. Prolonged exposure to silver nanoparticles results in oxidative stress in cerebral myelin. Neurotox. Res. 35, 495-504. https://doi.org/10.1007/s12640-018-9977-0.

Dahms, H.U., Hellio, C., 2009. Chapter 12: laboratory based assays for antifouling compounds. In: Yebra, S., Hellio, C. (Eds.), Advances in Antifouling Coatings and Technologies. Woodhead Publishers, Oxford, Cambridge, New Delhi, pp. 275-307.

Dahms, H.U., Hagiwara, A., Lee, J.S., 2011. Ecotoxicology, ecophysiology, and mechanistic studies with rotifers. Aquat. Toxicol. 101, 1-12. https://doi.org/ 10.1016/j.aquatox.2010.09.006.

Darlington, T.K., Neigh, A.M., Spencer, M.T., Nguyen, O.T., Oldenburg, S.J., 2009. Nanoparticle characteristics affecting environmental fate and transport through soil. Environ. Toxicol. Chem. 28, 1191-1199. https://doi.org/10.1897/08-341.1.

Esplugas, S., Bila, D.M., Krause, L.G.T., Dezotti, M., 2007. Ozonation and advanced oxidation technologies to remove endocrine disrupting chemicals (EDCs) and pharmaceuticals and personal care products (PPCPs) in water effluents. J. Hazard. Mater. 149, 631-642. https://doi.org/10.1016/j.jhazmat.2007.07.073.

Fan, W., Liang, D., Wang, X., Ren, J.Q., Xiao, S., Zhou, T., 2019. Two-generational effects and recovery of arsenic and arsenate on Daphnia magna in the presence of nano-TiO 2. Ecotoxicol. Environ. Saf. 172, 136-143. https://doi.org/10.1016/j. ecoenv.2019.01.072.

Finney, D.J., 1971. Probit Analysis, 3rd edn. Cambridge University Press, Cambridge. https://doi.org/10.1002/jps.2600600940.

Frattini, A., Pellegri, N., Nicastro, D., De Sanctis, O., 2005. Effect of amine groups in the synthesis of Ag nanoparticles using aminosilanes. Mater. Chem. Phys. 94, 148-152. https://doi.org/10.1016/j.matchemphys.2005.04.023.

Garner, K.L., Suh, S., Lenihan, H.S., Keller, A.A., 2015. Species sensitivity distributions for engineered nanomaterials. Environ. Sci. Technol. 49, 5753-5759. https://doi. org/10.1021/acs.est.5b00081.

Gómez, A., Serra, M., Carvalho, G.R., Lunt, D.H., 2002. Speciation in ancient cryptic species complexes: evidence from the molecular phylogeny of Brachionus plicatilis (Rotifera). Evolution (N. Y). 56, 1431-1444. https://doi.org/10.1111/j.00143820.2002.tb01455.x. 
Hagiwara, A., Balompapueng, M.D., Munuswamy, N., Hirayama, K., 1997. Mass production and preservation of the resting eggs of the euryhaline rotifer Brachionus plicatilis and B. Rotundiformis. Aquaculture 155, 223-230. https://doi.org/10.1016/ S0044-8486(97)00119-1.

Hagiwara, A., Suga, K., Akazawa, A., Kotani, T., Sakakura, Y., 2007. Development of rotifer strains with useful traits for rearing fish larvae. Aquaculture 268, 44-52. https://doi.org/10.1016/j.aquaculture.2007.04.029.

Hsin, Y.H., Chen, C.F., Huang, S., Shih, T.S., Lai, P.S., Chueh, P.J., 2008. The apoptotic effect of nanosilver is mediated by a ROS- and JNK-dependent mechanism involving the mitochondrial pathway in NIH3T3 cells. Toxicol. Lett. 179, 130-139. https:// doi.org/10.1016/j.toxlet.2008.04.015.

Huang, H.L., Wang, H.P., Wei, G.T., Sun, I.W., Huang, J.F., Yang, Y.W., 2006. Extraction of nanosize copper pollutants with an ionic liquid. Environ. Sci. Technol. 40, 4761-4764. https://doi.org/10.1021/es060034s.

Jain, P.K., Huang, X., El-Sayed, I.H., El-Sayed, M.A., 2008. Noble metals on the nanoscale: optical and photothermal properties and some applications in imaging, sensing, biology, and medicine. Acc. Chem. Res. 41, 1578-1586. https://doi.org/ 10.1021/ar7002804.

Jo, H.J., Choi, J.W., Lee, S.H., Hong, S.W., 2012. Acute toxicity of Ag and CuO nanoparticle suspensions against Daphnia magna: The importance of their dissolved fraction varying with preparation methods. J. Hazard. Mater. 227-228, 301-308. https://doi.org/10.1016/j.jhazmat.2012.05.066.

Kachynski, A.V., Kuzmin, A.N., Nyk, M., Roy, I., Prasad, P.N., 2008. Zinc oxide nanocrystals for nonresonant nonlinear optical microscopy in biology and medicine. J. Phys. Chem. C 112, 10721-10724. https://doi.org/10.1021/jp801684j.

Karlsson, H.L., Gustafsson, J., Cronholm, P., Möller, L., 2009. Size-dependent toxicity of metal oxide particles-A comparison between nano- and micrometer size. Toxicol. Lett. 188, 112-118. https://doi.org/10.1016/j.toxlet.2009.03.014.

Kasemets, K., Ivask, A., Dubourguier, H.C., Kahru, A., 2009. Toxicity of nanoparticles of $\mathrm{ZnO}, \mathrm{CuO}$ and $\mathrm{TiO} 2$ to yeast Saccharomyces cerevisiae. Toxicol. In Vitro 23 1116-1122. https://doi.org/10.1016/j.tiv.2009.05.015.

Khan, I., Raza, M.A., Bin Khalid, M.H., Awan, S.A., Raja, N.I., Zhang, X., Min, S., Wu, B. C., Hassan, M.J., Huang, L., 2019. Physiological and biochemical responses of pear millet (Pennisetum glaucum L.) seedlings exposed to silver nitrate $\left(\mathrm{AgNO}_{3}\right)$ and silver nanoparticles (AgNPs). Int. J. Environ. Res. Public Health 16, 1-17. https://doi.org/ 10.3390/ijerph16132261.

Kilham, S.S., Kreeger, D.A., Lynn, S.G., Goulden, C.E., Herrera, L., 1998. COMBO: a defined freshwater culture medium for algae and zooplankton. Hydrobiologia 377, 147-159. https://doi.org/10.1023/A:1003231628456.

Kim, S., Choi, J.E., Choi, J., Chung, K.H., Park, K., Yi, J., Ryu, D.Y., 2009. Oxidative stress-dependent toxicity of silver nanoparticles in human hepatoma cells. Toxicol. In Vitro 23, 1076-1084. https://doi.org/10.1016/j.tiv.2009.06.001.

Kwok, K.W.H., Dong, W., Marinakos, S.M., Liu, J., Chilkoti, A., Wiesner, M.R., Chernick, M., Hinton, D.E., 2016. Silver nanoparticle toxicity is related to coating materials and disruption of sodium concentration regulation. Nanotoxicology 10, 1306-1317. https://doi.org/10.1080/17435390.2016.1206150.

Lens, M., 2009. Use of fullerenes in cosmetics. Recent Pat. Biotechnol. 3, 118-123. https://doi.org/10.2174/187220809788700166.

Luoma, S.N., 2008. Silver Nanotechnologies and the Environment: Old Problems or New Challenges? Proj. Emerg. Nanotechnologies. Woodrow Wilson Centre, Washington, DC, USA, p. 72.

Manusadžianas, L., Caillet, C., Fachetti, L., Gylyte, B., Grigutyte, R., Jurkoniene, S., Karitonas, R., Sadauskas, K., Thomas, F., Vitkus, R., Férard, J.F., 2012. Toxicity of copper oxide nanoparticle suspensions to aquatic biota. Environ. Toxicol. Chem. 31, 108-114. https://doi.org/10.1002/etc.715.

Marcial, H.S., Hagiwara, A., Snell, T.W., 2005. Effect of some pesticides on reproduction of rotifer Brachionus plicatilis Müller. Hydrobiologia 546, 569-575. https://doi.org/ 10.1007/s10750-005-4302-3.

Martins, A., Guilhermino, L., 2018. Transgenerational effects and recovery of microplastics exposure in model populations of the freshwater cladoceran Daphnia magna Straus. Sci. Total Environ. 631-632, 421-428. https://doi.org/10.1016/j. scitotenv.2018.03.054.

Mendes, L.A., Maria, V.L., Scott-Fordsmand, J.J., Amorim, M.J.B., 2018. Multigenerational exposure of Folsomia candida to silver: effect of different contamination scenarios (continuous versus pulsed and recovery). Sci. Total Environ. 631-632, 326-333. https://doi.org/10.1016/j.scitotenv.2018.02.332.

Muna, M., Heinlaan, M., Blinova, I., Vija, H., Kahru, A., 2017. Evaluation of the effect of test medium on total $\mathrm{Cu}$ body burden of nano CuO-exposed Daphnia magna: a TXRF spectroscopy study. Environ. Pollut. 231, 1488-1496. https://doi.org/10.1016/j. envpol.2017.07.083.
Musee, N., 2011. Simulated environmental risk estimation of engineered nanomaterials: a case of cosmetics in Johannesburg City. Hum. Exp. Toxicol. 30, 1181-1195. https://doi.org/10.1177/0960327110391387.

Pan, J.F., Wang, W.X., 2004. Influences of dissolved and colloidal organic carbon on the uptake of Ag, Cd, and $\mathrm{Cr}$ by the marine mussel Perna viridis. Environ. Pollut. 129, 467-477. https://doi.org/10.1016/j.envpol.2003.11.015.

Perelaer, J., Hendriks, C.E., De Laat, A.W.M., Schubert, U.S., 2009. One-step inkjet printing of conductive silver tracks on polymer substrates. Nanotechnology 20. https://doi.org/10.1088/0957-4484/20/16/165303.

Peters, R.J.B., van Bemmel, G., Milani, N.B.L., den Hertog, G.C.T., Undas, A.K., van der Lee, M., Bouwmeester, H., 2018. Detection of nanoparticles in Dutch surface waters. Sci. Total Environ. 621, 210-218. https://doi.org/10.1016/j.scitotenv.2017.11.238.

Petersen, E.J., Nelson, B.C., 2010. Mechanisms and measurements of nanomaterialinduced oxidative damage to DNA. Anal. Bioanal. Chem. 398, 613-650. https://doi. org/10.1007/s00216-010-3881-7.

Pradhan, A., Seena, S., Pascoal, C., Cássio, F., 2011. Can metal nanoparticles Be a threat to microbial decomposers of plant litter in streams? Microb. Ecol. 62, 58-68. https:// doi.org/10.1007/s00248-011-9861-4.

Pradhan, A., Seena, S., Dobritzsch, D., Helm, S., Gerth, K., Dobritzsch, M., Krauss, G.J., Schlosser, D., Pascoal, C., Cássio, F., 2014. Physiological responses to nanoCuO in fungi from non-polluted and metal-polluted streams. Sci. Total Environ. 466-467, 556-563. https://doi.org/10.1016/j.scitotenv.2013.07.073.

Pradhan, A., Seena, S., Schlosser, D., Gerth, K., Helm, S., Dobritzsch, M., Krauss, G.J., Dobritzsch, D., Pascoal, C., Cássio, F., 2015. Fungi from metal-polluted streams may have high ability to cope with the oxidative stress induced by copper oxide nanoparticles. Environ. Toxicol. Chem. 34, 923-930. https://doi.org/10.1002/ etc. 2879.

Ren, G., Hu, D., Cheng, E.W.C., Vargas-Reus, M.A., Reip, P., Allaker, R.P., 2009. Characterisation of copper oxide nanoparticles for antimicrobial applications. Int. J. Antimicrob. Agents 33, 587-590. https://doi.org/10.1016/j. ijantimicag.2008.12.004.

Ribeiro, F., Van Gestel, C.A.M., Pavlaki, M.D., Azevedo, S., Soares, A.M.V.M., Loureiro, S., 2017. Bioaccumulation of silver in Daphnia magna: waterborne and dietary exposure to nanoparticles and dissolved silver. Sci. Total Environ. 574, 1633-1639. https://doi.org/10.1016/j.scitotenv.2016.08.204.

Rossbach, L.M., Maremonti, E., Eide, D.M., Oughton, D.H., Brede, D.A., 2019. Adaptive tolerance to multigenerational silver nanoparticle (NM300K) exposure by the nematode Caenorhabditis elegans is associated with increased sensitivity to $\mathrm{AgNO}_{3}$. Nanotoxicology 13, 527-542. https://doi.org/10.1080/17435390.2018.1557272.

Schultz, C.L., Wamucho, A., Tsyusko, O.V., Unrine, J.M., Crossley, A., Svendsen, C., Spurgeon, D.J., 2016. Multigenerational exposure to silver ions and silver nanoparticles reveals heightened sensitivity and epigenetic memory in Caenorhabditis elegans. Proc. R. Soc. B Biol. Sci 283. https://doi.org/10.1098/ rspb.2015.2911.

Snell, T.W., Hicks, D.G., 2011. Assessing toxicity of nanoparticles using Brachionus manjavacas (Rotifera). Environ. Toxicol. 26, 146-152. https://doi.org/10.1002/ tox. 20538.

Snell, T.W., Janssen, C.R., 1995. Rotifers in ecotoxicology: a review. Hydrobiologia 313-314, 231-247. https://doi.org/10.1007/BF00025956.

Tungittiplakorn, W., Lion, L.W., Cohen, C., Kim, J.Y., 2004. Engineered polymeric nanoparticles for soil remediation. Environ. Sci. Technol. 38, 1605-1610. https:// doi.org/10.1021/es0348997.

U.S. Environmental Protection Agency, 1985. Methods for Measuring the Acute.

Vandegehuchte, M.B., Lemière, F., Vanhaecke, L., Vanden Berghe, W., Janssen, C.R., 2010. Direct and transgenerational impact on Daphnia magna of chemicals with a known effect on DNA methylation. Comp. Biochem. Physiol. - C Toxicol. Pharmacol. 151, 278-285. https://doi.org/10.1016/j.cbpc.2009.11.007.

Wei, D., Unalan, H.E., Han, D., Zhang, Q., Niu, L., Amaratunga, G., Ryhanen, T., 2008. A solid-state dye-sensitized solar cell based on a novel ionic liquid gel and $\mathrm{ZnO}$ nanoparticles on a flexible polymer substrate. Nanotechnology 19, 2-7. https://doi. org/10.1088/0957-4484/19/42/424006.

Wu, H.P., Liu, J.F., Wu, X.J., Ge, M.Y., Wang, Y.W., Zhang, G.Q., Jiang, J.Z., 2006. High conductivity of isotropic conductive adhesives filled with silver nanowires. Int. J. Adhes. Adhes. 26, 617-621. https://doi.org/10.1016/j.ijadhadh.2005.10.001.

Yu, Z.Y., Chen, X.X., Zhang, J., Wang, R., Yin, D.Q., 2013. Transgenerational effects of heavy metals on L3 larva of Caenorhabditis elegans with greater behavior and growth inhibitions in the progeny. Ecotoxicol. Environ. Saf. 88, 178-184. https://doi.org/ 10.1016/j.ecoenv.2012.11.012. 